\title{
Resuscitative hypothermia after cardiac arrest in adults
}

Over the past 30 years, the fundamental principles of resuscitation following cardiac arrest have remained largely unchanged. Attempts to restore the circulation are based initially on external support of the circulation and respiration with defibrillation and drug therapy to achieve definitive treatment. Unfortunately, return of spontaneous circulation (ROSC) does not always equate with a successful outcome for the patient. It has been estimated that in the USA, of those patients 'successfully' resuscitated, $60 \%$ die as a result of brain injury [1] and only $3-10 \%$ resume their former life-style. Similarly, dismal results have been reported following out-of-hospital cardiac arrest [2,3] and after in-hospital cardiac arrest. Madl and colleagues [4] found that of those patients admitted to the intensive care unit (ICU) with ROSC, only $25 \%$ were discharged with a cerebral performance category score of 1 or 2 (good recovery or moderate disability). Such consistently poor outcomes, often after cardiac arrest lasting little more than $5 \mathrm{~min}$, have prompted many researchers in this field to investigate pharmacotherapeutic methods to try and ameliorate brain injury. A long list of adjuvants has been tried in man, but consistently failed to significantly improve outcome [5-11]. However, recently, there has been considerable encouragement by the findings in two independent studies that in adult, victims of cardiac arrest secondary to ventricular fibrillation, mild hypothermia induced after ROSC appears to be beneficial $[12,13]$.

Therapeutic hypothermia is not a new concept. Moderate hypothermia $\left(28-32^{\circ} \mathrm{C}\right)$ was first described in the early 1950 s to protect the brain against the global ischaemia that occurs during some cardiac surgery [14] and by the early 1960s had become standard practice in this type of surgery. The first successful use of therapeutic hypothermia after cardiac arrest in man was described in the late 1950s [15,16], but did not gain favour and was subsequently abandoned. While the reasons for this are unclear, it was probably because of the uncertain benefits and difficulties with its application [17]; particularly, when compared with

Correspondence to: Carl Gwinnutt, Department of Anaesthesia, Hope Hospital, Salford M6 8HD, UK. E-mail: carl.gwinnutt@srht.nhs.uk; Tel: +44 161787 5107; Fax: +441617874677

Accepted for publication January 2003 EJA 1413 the advent of external defibrillation [18], mouth-tomouth ventilation [19] and closed-chest cardiac compression [20], all of which occurred at around the same time.

Research in therapeutic hypothermia after cardiac arrest was not rejuvenated until the late 1980s. At this time, Safar and colleagues discovered that mild hypothermia, accidentally present during cardiac arrest in a dog model, appeared to mitigate hypoxic brain injury [21]. Subsequently, in a series of animal studies, they demonstrated that mild hypothermia, induced during resuscitation, was associated with improved functional recovery and reduced-cerebral histological deficits [22-24]. The combination of hypothermia with haemodilution and hypertension to promote cerebral blood flow resulted in the best functional and histological outcome in this model of cardiac arrest [25]. Unfortunately, the benefits of hypothermia appeared to be lost when onset was even minimally delayed (15 min) until after ROSC [26].

In 1997, Bernard and colleagues reported their preliminary results of the use of mild hypothermia in comatosed survivors of out-of-hospital cardiac arrest [27]. The neurological outcome of 22 patients in whom mild hypothermia was induced on arrival in the emergency department and maintained for $12 \mathrm{~h}$ was compared with 22 historic case-matched controls. They found a significant improvement in Glasgow Outcome Scores (GOS) and a reduction in mortality in those patients who had a period of hypothermia, with little evidence of any increase in complications. Subsequently, Yanagawa and colleagues [28] were unable to confirm these findings. In a smaller group of patients $(n=13)$, they found no difference in outcome at 6 months compared to historic controls and an increase in pneumonic complications. In 2000, Zeiner and colleagues reported the results of a feasibility trial of hypothermia after cardiac arrest [29]. Mild hypothermia was induced in comatosed survivors of out-ofhospital cardiac arrest using head and body surface cooling. This was started within 5 min of arrival in the emergency department and maintained for $24 \mathrm{~h}$. A twofold improvement in outcome occurred in those patients, who completed the study compared with historic controls and again no significant complications related to the use of hypothermia. The results of 
these studies were particularly encouraging because hypothermia appeared to be effective, despite not being induced until after ROSC, and often with significant delays in reaching target temperatures.

Both the most recent studies were prospective, randomized trials comparing treatment with mild hypothermia vs. normothermia. The European study was conducted in nine centres in five different countries [12], while the Australian study took place in four hospitals in Melbourne [13]. The criteria for entry into both trials were similar: out-of-hospital cardiac arrest in adults due to presumed ventricular fibrillation and persistent coma despite return of spontaneous circulation. In order to try and select patients most likely to benefit, exclusion criteria eliminated those patients with cardiac arrest of non-cardiac aetiology and those with severe cardiogenic shock. There were some differences between the two studies. In Europe, randomization using sealed envelopes occurred in the emergency department. Those assigned to hypothermia were cooled to a target temperature of $32-34^{\circ} \mathrm{C}$ using cold air delivered over the body surface plus ice packs, if necessary ( $70 \%$ of patients), the aim being to reach the target temperature within $4 \mathrm{~h}$ of ROSC. This was then maintained for $24 \mathrm{~h}$ after which patients were rewarmed passively. In Australia, pseudo-randomization (odd vs. even numbered days) was used to allocate patients to the treatment group. This enabled paramedics to commence cooling using cold packs to the head and torso before arrival at hospital. The target temperature was $33^{\circ} \mathrm{C}$, maintained for $12 \mathrm{~h}$ after admission after which active rewarming commenced at $18 \mathrm{~h}$.

The primary outcome measure, defined prospectively by both groups, was a favourable neurological outcome (Cerebral Performance Category (CPC) 1 or 2 in Europe, discharge to home or rehabilitation facility in Australia). In Europe, 275 patients were entered into the study over nearly $5 \mathrm{yr}$. In the hypothermia group, of the 136 patients for whom data were available, $75(55 \%)$ had a favourable neurological outcome at 6 months, compared with 54 of 137 (39\%) in the normothermia group (relative risk (RR): $1.40 ; 95 \%$ confidence interval (CI): 1.08-1.81; number needed to treat (NNT): 6). At 6 months, 56/137 (41\%) patients had died in the hypothermia group vs. $76 / 138(55 \%)$ in the normothermia group (RR: $0.74 ; 95 \% \mathrm{CI}$ : 0.58-0.95; NNT: 7). The target temperature could not be achieved in 19 of the patients in the hypothermia group. In the Australian study, 77 patients were randomized over a period of nearly $3 \mathrm{yr}$. In the hypothermia group, 21/43 (49\%) patients had good neurological function at discharge compared with $9 / 34$ $(26 \%)$ in the normothermia group (RR: $1.85 ; 95 \%$ CI: 0.97-3.49; NNT: 4). Mortality at discharge was $22 / 43(51 \%)$ in the hypothermia group and $23 / 34$
$(68 \%)$ in the normothermia group (RR: $0.76 ; 95 \%$ CI: 0.52-1.10; NNT: 6).

Both studies are open to criticism, but of the two, the European study is methodologically the stronger. It is obviously impossible to blind the clinicians involved in the care of these patients, which can introduce bias. The European study involved a highly selected group of patients; of the patients assessed, less than $10 \%$ (275/3551) were enrolled. The number of patients assessed in the Australian study is not stated, but enrolment of only 84 patients over $3 \mathrm{yr}$ suggests a similar degree of selectivity. Some patients in the normothermia group had an increase in core temperature after return of spontaneous circulation to as high as over $38^{\circ} \mathrm{C}$, as is often seen after cardiac arrest and which is known to be detrimental [30,31].

Although both groups reported no significant increase in the rate of complications in those patients treated with hypothermia, the Australian hypothermia group had a lower cardiac index, higher systemic vascular resistance and more hyperglycaemia than patients in the control group. In Europe, there were $22 \%$ more complications in the hypothermia group, in particular pneumonia, bleeding and sepsis.

\section{How does it work?}

It was originally believed that the benefits of hypothermia were due to a reduction in cerebral oxygen requirements. In the normal brain, the cerebral metabolic rate for oxygen decreases by approximately $50 \%$ for an $8^{\circ} \mathrm{C}$ reduction in brain temperature [32], an effect due to a reduction in both normal electrical activity and metabolic activity responsible for cellular integrity. While this may help explain a protective effect during periods of cerebral ischaemia, much of the neuronal damage seen is due to 'reperfusion injury', resulting in death of neurons, particularly in the vulnerable regions of the hippocampus and cerebellum. As cerebral blood flow is restored, oxidative metabolism of arachidonic acid generates free radicals, leading to peroxynitrite production, lipid peroxidation and cell membrane damage. The sudden restoration of intracellular ATP results in phosphorylation and inhibition of factors responsible for translation and initiation of protein synthesis, thereby inhibiting cell repair, while simultaneously signalling for apoptosis. At the same time, increased catecholamine concentrations, both endogenous and exogenous, reduce insulin secretion causing inhibition of growth factor receptor tyrosine kinase activity, further inhibiting protein synthesis and impairing mitochondrial resistance to free radical damage [33-35]. Unlike when a drug has been used to block a single facet of this onslaught, hypothermia may provide protection against many of these deleterious biochemical mechanisms. 
On the basis of the current evidence, should we be using mild hypothermia in cardiac arrest patients who remain comatose after ROSC? In their editorial, Safar and Kochanek recommend 'the use of mild hypothermia in survivors of cardiac arrest - as early as possible and for at least $12 \mathrm{~h}$ ' [36]. It would be hard to refute this suggestion for those patients who fit the criteria used in the European and Australian studies. How easy would it be for us to follow these recommendations? The treatment of most of these patients will include admission to a critical care unit for a period of sedation, ventilation and haemodynamic monitoring. The addition of therapeutic mild hypothermia would not be too difficult to achieve nor would it extend significantly the length of stay on the critical care unit. What about extending this therapeutic option to those patients who remain comatose after in-hospital cardiac arrest? Although many in-hospital cardiac arrests are non-cardiac in origin [37] and the role of hypothermia has not been studied extensively in this group of patients, it is entirely possible that those patients who remain comatose after in-hospital arrest of cardiac aetiology might benefit. Further support for the use of mild hypothermia in specific circumstances is expected very shortly in the form of an advisory statement from the International Liaison Committee on Resuscitation (ILCOR).

\section{Cooling techniques and monitoring}

External cooling techniques are easy to apply, but are not efficient at reducing core temperature. Techniques include: cooling blankets, ice packs to the groins, axillae and neck, wet towels and fanning, and a cooling helmet [38]. An intravenous (i.v.) infusion of $30 \mathrm{~mL} \mathrm{~kg}^{-1}$ of crystalloid at $4^{\circ} \mathrm{C}$ over 30 min reduces core temperature significantly [39]. Extracorporeal cooling methods are efficient [40], but too invasive to apply in the pre-hospital environment and most emergency departments. An intravascular heat exchange device that enables rapid, precise cooling is now available [41].

During cooling, shivering must be prevented with neuromuscular block and sedation. Careful temperature monitoring is important as the incidence of complications, particularly dysrhythmias, infection and coagulopathy increase, if core temperature falls below $32^{\circ} \mathrm{C}$. Continuous temperature monitoring can be undertaken with a bladder probe or a pulmonary artery catheter.

\section{The future}

Following cardiac arrest, achieving ROSC remains the first and most important step towards patient survival. Therefore, we must continue our efforts to determine those interventions that improve the chances of ROSC. However, we must be mindful that in man, cardiac arrest lasting more than $5 \mathrm{~min}$ is associated with a poor outcome, usually, as a result of cerebral damage caused by global ischaemia and reperfusion injury. This has been termed the 'metabolic phase' of resuscitation, and therapeutic interventions targeted at this phase will be required in those patients, where the circulation is absent for a prolonged period [42]. Mild hypothermia would appear to be an effective therapy for this phase of resuscitation, but many questions now remain to be answered. What is the best method of cooling, how fast and for how long? Is $33-34^{\circ} \mathrm{C}$ optimal and how should the patient be rewarmed? Finally, would the use of adjunctive therapy, such as antioxidants, further enhance the effects of hypothermia [43]? We await further studies in the use of mild hypothermia in patients, who remain comatose after resuscitation from cardiac arrest with great interest.

$$
\begin{array}{r}
\text { C. L. Gwinnutt } \\
\text { Department of Anaesthetics } \\
\text { Hope Hospital, Salford, UK } \\
\text { J. P. Nolan } \\
\text { Department of Anaesthetics } \\
\text { Royal United Hospital, Bath, UK }
\end{array}
$$

\section{References}

1. Krause GS, Kumar K, White BC, Aust SD, Wiegenstein JG. Ischemia, resuscitation, and reperfusion: mechanisms of tissue injury and prospects for protection. Am Heart $J$ 1986; 111: 768-780.

2. Roine RO, Kajaste S, Kaste M. Neuropsychological sequelae of cardiac arrest. JAMA 1993; 269: 237-242.

3. Bernard S. Outcome from prehospital cardiac arrest in Melbourne, Australia. Emerg Med 1998; 10: 25-29.

4. Madl C, Grimm G, Kramer L, et al. Early prediction of individual outcome after cardiopulmonary resuscitation. Lancet 1993; 341: 855-858.

5. Brain Resuscitation Clinical Trial I Study Group. Randomized clinical study of thiopental loading in comatose survivors of cardiac arrest. N Engl J Med 1986; 31: 379-403.

6. Brain Resuscitation Clinical Trial II Study Group. A randomized clinical study of a calcium-entry blocker (lidoflazine) in the treatment of comatose survivors of cardiac arrest. N Engl J Med 1991; 324: 1225-1231.

7. Roine RO, Kaste M, Kinnunen A, Sarna S, Kajaste S. Nimodipine after resuscitation from out-of-hospital ventricular fibrillation. A placebo-controlled, double-blind, randomized trial. JAMA 1990; 264: 3171-3177.

8. Jastremi M, Sutton-Tyrrell K, Vaagenes P, Abramson N, Heiselman D, Safar P. Glucocorticoid treatment does not improve neurological recovery following cardiac arrest. Brain Resuscitation Clinical Trial I Study Group. JAMA 1989; 262: 3427-3430. 
9. Woods RJ, Prueckner S, Safar P, et al. Adenosine by aortic flush fails to augment the brain preservation effect of mild hypothermia during exsanguination cardiac arrest in dogs: an exploratory study. Resuscitation 2000; 44: 47-59.

10. Behringer W, Kentner R, Wu X, et al. Fructose-1,6 bisphosphate and MK-801 by aortic arch flush for cerebral preservation during exsanguination cardiac arrest of 20 minutes in dogs. An exploratory study. Resuscitation 2001; 50: 205-216.

11. Behringer W, Kentner R, Wu X, et al. Thiopental and phenytoin by aortic arch flush for cerebral preservation during exsanguination cardiac arrest of 20 minutes in dogs. An exploratory study. Resuscitation 2001; 49: 83-97.

12. The Hypothermia after Cardiac Arrest Study Group. Mild therapeutic hypothermia to improve the neurologic outcome after cardiac arrest. N Engl J Med 2002; 346: 549-556.

13. Bernard SA, Gray TW, Buist MD, et al. Treatment of comatose survivors of out-of-hospital cardiac arrest with induced hypothermia. N Engl J Med 2002; 346: 557-563.

14. Bigelow WG, Lindsay WK, Greenwood WF. Hypothermia: its possible role in cardiac surgery. Ann Surg 1950; 132: 849-866.

15. Williams GR, Spencer FC. The clinical use of hypothermia following cardiac arrest. Ann Surg 1958; 148: 462-466.

16. Benson DW, Williams GR, Spencer FC, Yates AJ. The use of hypothermia after cardiac arrest. Anesth Analg 1959; 38: 423-428.

17. Marion DW, Leonov Y, Ginsberg M, et al. Resuscitative hypothermia. Crit Care Med 1996; 24 (Suppl 2): S81-S89.

18. Zoll PM, Linenthal AJ, Gibson W, Paul MH, Normal LR. Termination of ventricular fibrillation in man by externally applied electric countershock. N Engl J Med 1956; 254: 727-732.

19. Safar P, Escarraga L, Elam J. A comparison of the mouthto-mouth and mouth-to-airway methods of artificial respiration with the chest-pressure arm-lift methods. $N$ Engl J Med 1958; 258: 671-677.

20. Kowenhoven WB, Jude JR, Knickerbocker GG. Closedchest cardiac massage. JAMA 1960; 173: 1064-1067.

21. Safar P, Behringer W, Bottiger BW, Sterz F. Cerebral resuscitation potentials for cardiac arrest. Crit Care Med 2002; 30: S140-S144.

22. Leonov Y, Sterz F, Safar P, et al. Mild cerebral hypothermia during and after cardiac arrest improves neurologic outcome in dogs. J Cereb Blood Flow Metab 1990; 10: 57-70.

23. Sterz F, Safar P, Tisherman S, Radovsky A, Kuboyama K, Oku K. Mild hypothermic cardiopulmonary resuscitation improves outcome after prolonged cardiac arrest in dogs. Crit Care Med 1991; 19: 379-389.

24. Weinrauch V, Safar P, Tisherman S, Kuboyama K, Radovsky A. Beneficial effect of mild hypothermia and detrimental effect of deep hypothermia after cardiac arrest in dogs. Stroke 1992; 23: 1454-1462.

25. Safar P, Xiao F, Radovsky A, et al. Improved cerebral resuscitation from cardiac arrest in dogs with mild hypothermia plus blood flow promotion. Stroke 1996; 27: 105-113.

26. Kuboyama K, Safar P, Radovsky A, Tisherman S, Stezoski W, Alexander H. Delay in cooling negates the beneficial effect of mild resuscitative cerebral hypothermia after cardiac arrest in dogs: a prospective, randomized study. Crit Care Med 1993; 21: 1348-1358.
27. Bernard S, Jones BMC, Horne MK. Clinical trial of induced hypothermia in comatose survivors of out-of-hospital cardiac arrest. Ann Emerg Med 1997; 30: 146-153.

28. Yanagawa $\mathrm{Y}$, Ishihara $\mathrm{S}$, Norio $\mathrm{H}$, et al. Preliminary clinical outcome study of mild resuscitative hypothermia after out-of-hospital cardiopulmonary arrest. Resuscitation 1998; 39: 61-66.

29. Zeiner A, Holzer M, Sterz F, et al. Mild resuscitative hypothermia to improve neurological outcome after cardiac arrest. A clinical feasibility trial. Hypothermia After Cardiac Arrest (HACA) Study Group. Stroke 2000; 31: 86-94.

30. Dietrich WD, Busto R, Valdes I, Loor Y. Effect of normothermic versus mild hyperthermic forebrain ischemia in rats. Stroke 1990; 21: 1318-1325.

31. Dietrich WD, Busto R, Halley M, Valdes I. The importance of brain temperature in alterations of the blood-brain barrier following cerebral ischemia. $J$ Neuropathol Exp Neurol 1990; 49: 486-497.

32. Steen PA, Newberg L, Milde J, Michenfelder JD. Hypothermia and barbiturates: individual and combined effects on canine cerebral oxygen consumption. Anesthesiology 1983; 58: 527-532.

33. White BC, Sullivan JM, DeGracia DJ, et al. Brain ischaemia and reperfusion: molecular mechanisms of neuronal injury. J Neurol Sci 2000; 179: 1-33.

34. D'Cruz BJ, Fertig KC, Filiano AJ, Hicks SD, DeFranco DB, Callaway CW. Hypothermic reperfusion after cardiac arrest augments brain-derived neurotrophic factor activation. J Cereb Blood Flow Metab 2002; 22: 848-851.

35. Hicks SD, DeFranco DB, Callaway CW. Hypothermia during reperfusion after asphyxial cardiac arrest improves functional recovery and selectively alters stress-induced protein expression. J Cereb Blood Flow Metab 2000; 20: 520-530.

36. Safar PJ, Kochanek PM. Therapeutic hypothermia after cardiac arrest. N Engl J Med 2002; 346: 612-613.

37. Gwinnutt CL, Columb M, Harris R. Outcome after cardiac arrest in adults in UK hospitals: effect of the 1997 guidelines. Resuscitation 2000; 47: 125-135.

38. Hachimi-Idrissi S, Corne L, Ebinger G, Michotte Y, Huyghens L. Mild hypothermia induced by a helmet device: a clinical feasibility study. Resuscitation 2001; 51: 275-281.

39. Bernard S, Buist M, Monterio O, Smith K. Induced hypothermia using large volume, ice-cold intravenous fluid in comatose survivors of out-of-hospital cardiac arrest: a preliminary report. Resuscitation 2003; 56: 9-13.

40. Nagao K, Hayashi N, Kanmatsuse K, et al. Cardiopulmonary cerebral resuscitation using emergency cardiopulmonary bypass, coronary reperfusion therapy and mild hypothermia in patients with cardiac arrest outside the hospital. J Am Coll Cardiol 2000; 36: 776-783.

41. Sterz F, Holzer M, Roine R, et al. Hypothermia after cardiac arrest: a treatment that works. Curr Opin Crit Care 2003 , in press.

42. Weisfeldt ML, Becker LB. Resuscitation after cardiac arrest. A 3-phase time-sensitive model. JAMA 2002; 288: 3035-3038.

43. Behringer WB, Safar P, Kentner R, et al. Antioxidant tempol enhances hypothermic cerebral preservation during prolonged cardiac arrest in dogs. J Cereb Blood Flow Metab 2002; 22: 105-117. 